UMR 5824

93. chemin des Mouilles 69130 Ecully - France

Maison de IUniversité, Bâtiment $\mathrm{B}$ 10, rue Trefilerie 42023 Saint-Etienne cedex $02 \cdot$ France http://www.gate.cnrs.fr gate@gate.cnrs.fr

\title{
Mother's Education and Increased Child Survival in Madagascar: What Can We Say?
}

\author{
Samia Badji
}

\begin{abstract}
:
This paper aims to assess whether a causal effect exists between maternal education and child survival in Madagascar. The omission of factors such as mother's health, innate ability and time preferences could lead to an overestimation of the true effect of education. The case of sub-Saharan Africa where child mortality rates are the highest, is overlooked by most of the causal evidence gathered so far for developing countries. The present paper attempts to redress this omission through the adoption of a careful empirical strategy. The analysis sheds light on the mechanisms at stake based on information on hygiene practices, housing conditions and the health care administered before, during and after childbirth. The results demonstrate that mothers' education has a positive and strong effect on their offsprings' survival probabilities. Wealth on its own has a strong effect but seems to account for only a third of the effect of maternal education.
\end{abstract}

\section{Keywords:}

child mortality, mother's education, Africa, Madagascar

JEL codes:

I10, I12, I26

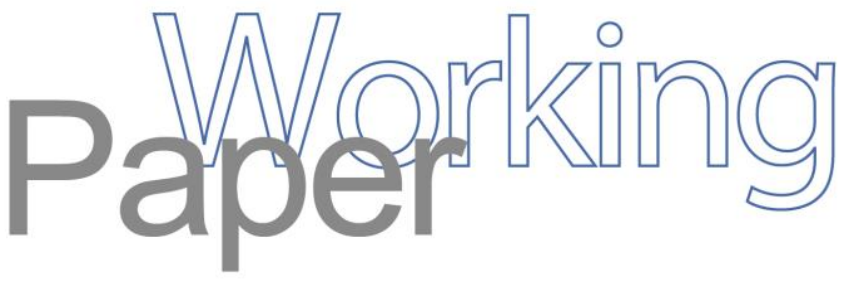




\title{
Mother's Education and Increased Child Survival in Madagascar: What Can We Say?
}

\author{
Samia Badji*
}

November 2016

\begin{abstract}
This paper aims to assess whether a causal effect exists between maternal education and child survival in Madagascar. The omission of factors such as mother's health, innate ability and time preferences could lead to an overestimation of the true effect of education. The case of sub-Saharan Africa where child mortality rates are the highest, is overlooked by most of the causal evidence gathered so far for developing countries. The present paper attempts to redress this omission through the adoption of a careful empirical strategy. The analysis sheds light on the mechanisms at stake based on information on hygiene practices, housing conditions and the health care administered before, during and after childbirth. The results demonstrate that mothers' education has a positive and strong effect on their offsprings' survival probabilities. Wealth on its own has a strong effect but seems to account for only a third of the effect of maternal education.
\end{abstract}

Keywords: child mortality; mother's education; Africa; Madagascar JEL classification: I10, I12, I26

${ }^{*}$ Univ Lyon, CNRS, GATE L-SE UMR 5824, F-69131 Ecully, France 


\section{Introduction}

In 2015, 5.9 million children died before reaching the age of five. Children in sub-Saharan Africa (SSA) are more than 14 times more likely than children from developed regions to die before the age of five ${ }^{1}$. Child mortality is tremendously important and a focus on SSA is crucial. This paper investigates one particular country in this region, Madagascar, where despite recent improvements, the child mortality figures are still alarming. Since child mortality is a leading indicator of the health of the surviving children as well as the whole population, the consequences of this go beyond the already shocking losses.

Caldwell's (1979) work and Hobcraft's (1993) review for developing countries suggest a strong link between child survival and child health on the one side, and maternal education on the other. The higher association between maternal education and child health and survival does not mean that the effect is causal, and the reasons for endogeneity are manifold. Parents with higher levels of education might display lower preferences for the present, have better health, or have an intrinsically greater ability to manage education and health. Chen and Li's (2009) study of adoptees in China shows that the effect of education on child health is similar for adoptees and own birth children suggesting that genetic factors might play only a small part. Time preferences, ability to take care of children and education preferences might be shared among household members. The two following studies examine the effect of mother's education while removing the family effect. Wolfe and Behrman (1987) study the case of Nicaragua using a special sample of households of adult female siblings and show no effect on child health. Handa (1999) explores a special feature of Jamaican households which is that they often include children from different mothers, in order to remove household level heterogeneity. She finds no effect of mother's

\footnotetext{
${ }^{1}$ WHO Fact sheet (2016)
} 
education on child height ${ }^{2}$.

Another strand in the literature investigates exogenous change in years of mandatory schooling or in school supply to instrument the effect of education. Doyle, Harmon and Walker (2005) analyze the impact in England of parental education and income on the health of offspring based on increased mandatory schooling and grand parents' smoking histories as instruments. Their results suggest a positive effect of mother's education on child health which becomes larger when endogeneity is accounted for. Chou, Liu, Grossman and Joyce (2007) use the increase in years of mandatory schooling combined with an increase in school supply as a natural experiment and find that parental schooling reduced child mortality by $11 \%$ in Taiwan. Breierova and Duflo (2004) use a massive school construction program in Indonesia interacted with parents' year of birth and confirm that parents' schooling has a strong and negative causal effect on child mortality. These two literature streams seem to provide conflicting results, the causal effect of maternal education is not clear and raises the question of how maternal education might affect child mortality.

Currie and Moretti (2003) examine the mechanisms in the United States using college availability when the mother was 17 . They suggest that educated mothers have healthier lifestyles, use more prenatal care, have lower expected fertility and are more likely to marry educated men, the latter particularly increasing the family income of educated women in developing countries. The child survival probability might be increased also by school attendance since being at school reduces the immediacy of the desire to bear children. Glick, Handy and Sahn (2015) offer a joint estimation of education and marriage age on age at first childbirth for Madagascar. Although education is not a significant determinant of age at first birth it delays marriage by 1.5 years which delays first birth by nine months.

\footnotetext{
${ }^{2}$ The effect without fixed effects was reduced considerably when the sample was restricted to households with more than one child.
} 
Finlay, Özaltin and Canning (2010) using a sample of 55 low-and-middle-income countries (including Madagascar), find evidence that poor child health and mortality decrease with mother's age: the risk of poor child health and mortality dissipates by age 21 and improvement continues up to 27-29 years.

Thomas, Strauss and Henriques (1991) use data on Brazil and find that almost all of the impact of mother's education could be explained by indicators of her access to information (through TV, radio or newspapers) suggesting that availability and processing of information play critical roles. Glewwe's (1999) results for Morocco seem to support their finding. He finds that acquisition of health knowledge is a leading factor and is enabled by literacy. Aslam and Kindgon (2012) investigate the causal effect of parental education in Pakistan accounting for potentially omitted variables. They find that father's education matters for immunization directly through health knowledge. Maternal education matters for stunting and wasting (but not immunization) which seems to be the result of their health knowledge and empowerment in the home.

Focusing on SSA, Caldwell's (1979) seminal article highlights the strong relationship between mother's education and lower child mortality in Nigeria, and proposes three explanations for why maternal education increases child survival. First, an educated mother might be less fatalistic about illness and seek care. Education increases both knowledge and the capacity to deal with new ideas and import different cultures. Second, she might become more able to interact with the modern world, that is, she might regard the facilities around her as a right, and interact more with medical staff. Third, she might have higher bargaining power not only with her husband but also with other family members such as parents in law. She might successfully impose her decisions and not be challenged since her education will affect how she is viewed by other household members. Bbaale and Buyinza (2011) uses DHS (Demographic and Health Surveys) data for Uganda to investigate mor- 
tality and find that maternal education matters to reduce mortality, and that education beyond primary school should be promoted. However, neither study takes account of the potential endogeneity of mother's education.

Maïga (2011) examines the causal effect of maternal education on child health using the expansion and extension of years of schooling from the "Ecoles satellites" project in Burkina Faso. She finds that maternal education has a strong and positive impact on child health. In the case of height-for-age all of the impact is captured by wealth. For weight-for-height, after including the effect of wealth, bargaining power, having a clinic nearby and health knowledge, mother's education still has an effect on its own. When investigating child health, the high child mortality rates are generally not taken into account although the survivor bias can be particularly serious in this region. Bharadwaj and Grépin (2015) specifically addresses child mortality in Zimbabwe using the increase in education that followed Zimbabwe's independence. They find that maternal education increases the survival probability of the children by $21 \%$ for each additional year of schooling. They do not find evidence of a stronger health-seeking behavior. In the same country, using the same identification strategy, Agüero and Bharadwaj's (2014) investigate a different health outcome. They analyze how education impact one's own HIV status. They find that more educated people do engage in health-seeking behaviors (although they are not significantly less likely to be HIV positive).

This paper assesses the causal effect of mother's education on child mortality in Madagascar. The investigation is facilitated by data from a a special survey which asked about school availability when the mother was aged ten. The total effect of education is examined, and then the partial effects are studied using rich information on health, hygiene and wealth. The results show that the exogeneity of maternal education cannot be rejected. Mothers's education has a causal effect on child mortality, and it seems that wealth ac- 
counts for approximately a third of the effect. The effect of mothers' education does not seem to be affected by measures for pre/post natal care, hygiene practices or vitamin A supplements.

The remainder of the paper is organized as follows. Section 2 describes the data. Section 3 presents the model. Section 4 presents and discusses the results. Section 5 investigates the mechanisms and section 6 concludes.

\section{Data and Descriptive Statistics}

The data were collected in 2006 in rural Madagascar for the EIFID (Etude d'Impact pour le Fonds d'Intervention du Développement). The household survey included 236 districts where only some villages/communities were surveyed. In each of the chosen communities, 18 households were selected representing a total of 23,185 individuals. The surveyed communes are slightly poorer and more isolated on average than the overall rural population which experiences higher child mortality rates and therefore is worthy of greater attention. The dataset is unique in containing an unusually high number of variables for access to health care such as immunization, perinatal care, and nutritional supplements

along with information on hygiene practices such as access to water and waste disposal methods. The data include specific information on housing and the durable assets owned by households allowing the construction of a wealth index based on the methodology in Filmer and Pritchett (2001).

To assess the representativeness of the survey, two mortality rates are computed: the number of children who died before age five and one respectively for all women in the survey, divided by the number of births for all women in the survey. The rates correspond 
to 185.77 and 114.89 respectively. The official child (infant) mortality rates correspond to the number of children who died before age five (one) per thousand births in a given period. Since the survey did not ask about the year of death, the child and infant mortality rates cannot be calculated and our rates are only rough indicators of the actual child and infant mortality rates. Our figures are higher than the available mortality rates for Madagascar from 1970 to $2006^{3}$ which is consistent with the fact that the sample is made up of slightly poorer and more isolated households.

Education in Madagascar is not widespread. The World Bank Education Statistics database indicates average years of schooling as 5.45 in 2005 for adults aged over 25. In our sample the average number of years spent at school is barely four with a median at three. The almost two year difference is due mainly to the aggregation with urban averages in the World Bank survey. Table 1 presents education by level, disaggregated by gender. It shows that a fifth of the 18 to 55 years old in the survey has no education, $60 \%$ have a level inferior to primary school, $18.5 \%$ stopped education after completing primary school and $12.5 \%$ have a level of schooling at least as high as middle school. Only $3 \%$ finished high school ${ }^{4}$. Consequently, one in four adults cannot read or write Malagasy, and one in two cannot read or write French, Madagascar's other official language. Since we focus on maternal education, we look at female education and table 1 shows that $76 \%$ of women were enrolled in school compared to $81 \%$ of men $^{5}$.

In relation to mortality, the situation in Madagascar is alarming. As many as one in

\footnotetext{
${ }^{3}$ Although not optimal giving equal weights to all years from 1970 to 2006 yields an average infant mortality rate of 91 and an average under five mortality rate of 148 .

${ }^{4}$ Since very few individuals have a level above middle school, middle school completed is the highest level shown. Table 2 in the appendix provides the distribution of education measured by years of schooling, completed high school referring to year 12 (primary school cycle lasts for five years, middle school four and high school three).

${ }^{5}$ The difference is statistically different from zero at the $1 \%$ level. However, the gender gap is lower compared to other developing countries.
} 
five mothers experience the death of a child. Of these, $40 \%$ experience two or more child deaths. Since child mortality is also an indicator of the health of surviving children, we need to look also at malnutrition where the figures are similarly dire. The survey shows that $50 \%$ of Madagascan children suffer from moderate malnutrition, and more than one in ten suffers from severe acute malnutrition which figure should be interpreted as a lower bound since it can be measured only for surviving children.

Child mortality measures can be regarded as extreme cases of malnutrition or bad health. Although child survival and child health might appear to be very different aspects, it is worth noting that the mechanisms investigated are similar, and the bias associated with maternal schooling is analogous. However, unlike morbidity measures child mortality is objective. Morbidity and more generally mother-reported measures are the sum of two effects. The first is the actual (bad) health status of the child. The second is the ability of the mother to notice the bad outcome. Some children might be sick but their mothers (most likely the less educated ones) might be unable to detect this. Sen (1998) points out that the perception of illness varies with medical knowledge but also with what is familiar to the individual. Ultimately, the coefficient of maternal education will be at best underestimated and at worst will show the opposite effect. Anthropometric measures offer an interesting alternative where a child's body measurements are compared to a sample of healthy children but when child mortality is high and more likely to occur in uneducated households, the survivor bias might alter the estimation (Boerma, Sommerfelt and Bicego; 1992) .

A potential drawback of our mortality measure is that it is reported by the mother. Beckett et al. (2001) examine the quality of retrospective data in a developing country and find some degradation in the data quality for details relative to an event but not its occurrence. They also find that the quality of long-term retrospective histories is almost 
equal to the quality of short-term ones so there should be no concern that older mothers provide less reliable data. In addition, mothers' reports might be more reliable than death certificates. Data regarding the completeness of death reportings are not available for Madagascar, however, birth registration completeness are available. In 2004, 74.8\% (72\% for rural areas) of births are registered and $79.7 \%$ ( $78.2 \%$ for rural areas) in 2009 (UNICEF). That is, roughly one in four births is not registered and there are no reasons to believe death registration rates are higher ${ }^{6}$.

Table 4 allows comparison of mortality intensity by level of maternal education ${ }^{7}$. It presents the number of children lost and the ratio of deaths to the number of live births for each level of education. The first line indicates zero children lost. It is directly comparable to the probability of having ever experienced a child loss. The ratio is similar except in taking account of the number of deaths along with the number of births ${ }^{8}$. The p-value in the last column tests whether uneducated women and educated women (having at least one year of education) have the same means. Any level of education above zero is associated with a decrease of at least two percentage points in the probability to lose a child, suggesting that mother's education has a negative impact on mortality ${ }^{9}$. The relationship becomes more striking if we look at the cases of two or more than two children lost. It is possible that uneducated women on average have more children, and that the previous observation is the result only of this higher fertility. The ratio of the number of children lost is however

\footnotetext{
${ }^{6}$ UNICEF data are partly based on the carer's statement therefore actual birth registration might be even lower.

${ }^{7}$ The statistics are provided for the sample of mothers who gave at least two births for reasons explained in the section on the instruments. Results are similar if women who ever had a live birth are examined. Conditioning on having lost a child, the likelihood to lose another child is still decreasing with education.

${ }^{8}$ Women with only one child under five and no child dead cannot be said to have not lost a child since it is not known yet. We still assume so and excluding them leads to similar results.

${ }^{9}$ The probability to lose a child (first line in table 4 ) is not statistically different at the conventional $10 \%$ level but is at $12 \%$. It is like a sum of tests of losing one, two or more children for which some test show statistical difference. Moreover the probability to lose a child is statistically different at the usual $10 \%$ threshold. For these two reasons, we can consider that the probability to experience a child loss is statistically different for educated and uneducated women.
} 
also lower for the more educated women though not statistically different.

Before looking at mechanisms that may explain differences in child mortality between educated and uneducated women, one may wonder whether mothers do raise their children themselves. Child fostering is not as widespread as in other SSA countries, but it is still significant. Rakato Tiana (2012) even finds evidence of differential treatment between fostered and non fostered children in terms of school attendance ${ }^{10}$ (once relationship to the household head is taken into account) in the hosting family. Among women who ever had a live birth, $18 \%$ have a child under 18 not living in the household. This may raise concerns especially if the decision to foster children is related to their health status. Unsurprisingly, the database does not provide information on fostering for deceased children. The health status could help however anthropometric measurements are only available for children present during the survey therefore not for fostered children. Since we are only looking at under five children, the impact of fostering should be quite limited since they represent only $6.5 \%$ of all under 18 year fostered children. Restricting to children who are not living with their mothers only $3 \%$ of fostered children are under five. In the end, given our outcomes of interest the impact of child fostering should be quite limited.

Table 5 presents the variables used to account for the mechanisms along with different health and control variables. The mean and standard deviations are reported along with the mean for different education levels. The penultimate column compares uneducated women to women with at least one year of schooling and gives the probability that the two samples have the same mean. The last column gives the correlations with education. Mother's age is significantly different across the samples, and is the main variable controlled for in the regression afterwards. Clearly, there is assortative mating: the correlation between

\footnotetext{
${ }^{10}$ She examines school attendance of fostered children compared to non fostered children in their host family which differs from comparing fostered to non fostered children in their original family.
} 
partner's education is positive and among the highest. Education is also an indicator of wealth, with the indicator for long term wealth (an asset index) showing a high and positive correlation with education. These are commonly used measures for wealth since wealth is difficult to measure and the measurements are subject to bias. Assets can be checked by the enumerator and avoid such bias. However, assets are more a measure of long term wealth, and to the extent that housing characteristics are taken into account, it might be linked also with the location ${ }^{11}$.

As discussed in the introduction, it seems that educated mothers have better hygiene practices as indicated by information on sanitation and disposal methods. Women with schooling tend to use more perinatal care shown by the positive correlation between education and taking iron supplements, having a postnatal medical check, taking vitamin A supplements, having a doctor present at childbirth or being vaccinated against tetanus ${ }^{12}$. Both mortality outcomes show lower incidence rates for mothers who went to school. However, educated people are also richer and more likely to use pre- and postnatal care. They seem to have better hygiene practices as reflected by drinking water source. More educated people are also more likely to use toilet although, like the previous variables, this might be the result of higher wealth. At this stage, it is not possible to say whether the lower averages for mortality found for educated mothers reflect a causal effect nor is it possible to assess whether the pre/post natal care variables are the mechanisms through which education plays a role if any.

\footnotetext{
${ }^{11}$ Since only rural households are surveyed, this should not have strong implications.

${ }^{12}$ Pregnant mothers are vaccinated to protect the child.
} 


\section{The model}

This section describes the empirical model and further develops how identification of the effect of mother education on child mortality is undertaken.

\subsection{Empirical model}

To examine child mortality in Madagascar, we use a simple reduced form model:

$$
Y_{m}=\gamma_{0}+\gamma_{1} S_{m}+\boldsymbol{A}_{\boldsymbol{m} \boldsymbol{h}} \Gamma_{3}+\boldsymbol{B}_{\boldsymbol{m} \boldsymbol{h}} \Gamma_{4}+u_{m}
$$

where $Y_{m}$ is a measure of child mortality, $A_{m h}$ is a set of control variables such as ethnic group, mother's age, and locality (or community) dummies, $B_{m h}$ is a set of channel variables and $S_{m}$ is mother's education. It is measured as years of schooling. It is introduced linearly since specifications with higher orders did not show a non-linear effect.

The two outcome variables described earlier are used to measure mortality. The first is a dummy variable indicating whether the mother has lost one (or more) child aged under five years. This variable is clearly linked to the number of children a woman has which can be argued to be defined by mother's schooling. For this reason, we also include a second variable: the ratio of the number of children who died to the number of children born (controlling for the number of children).

To limit the number of characteristics that might influence mortality, all the regressions include a set of control variables $\boldsymbol{A}_{\boldsymbol{m} \boldsymbol{h}}$. Different beliefs or preferences might drive both health care decisions and schooling decisions. To that extent, ethnic group dummies are introduced in $\boldsymbol{A}_{\boldsymbol{m} \boldsymbol{h}}$ with the Merina, the largest ethnic group in Madagascar, as the reference group ${ }^{13}$. Although mother's age at childbirth is important, this information is

\footnotetext{
${ }^{13}$ Because of the diversity of ethnic groups in Madagascar, non Merina are aggregated into six non Merina ethnic groups. There is an unfortunate loss of information but the sample size does not allow for better
} 
missing. Mother's current age is introduced in $\boldsymbol{A}_{\boldsymbol{m} \boldsymbol{h}}$ but it is more likely to embody the influence of mother's generation than mother's age at the birth of her children. Mother's age based on the above is included as dummies with five year intervals ${ }^{14}$.

Community fixed effects may influence both schooling infrastructure and mortality rates. They capture environmental characteristics such as infrastructure quality, and air/water quality over which a mother has very limited influence. If mothers have migrated, community fixed effects will fail to capture the prevailing characteristics in the childbirth area (provided that care and delivery took place in the previous locality). Since we have information on pre- and postnatal care for women who gave birth in the previous five years it should partly limit this problem. Moreover, most women (more than 80\%) have not migrated.

Finally, $B_{m h}$ is a set of variables to account for the channels through which education has an impact. These variables are wealth, hygiene practices (water and litter) and health care (prenatal care, postnatal care and delivery) which are added to the equation first one by one and then together. $u_{m}$ includes all other unobserved determinants such as parents' health, preferences and measurement errors. All results have clustered standard errors at the community level.

If time preferences and parents' health are strong factors of mortality then the results will be biased upward. The next subsection provides more details about the instruments used to account for potential endogeneity of mother's education.

treatment of the issue. Details of the aggregation are available upon request.

${ }^{14}$ To the extent that there might be concern that mother's age captures more than a generation effect, a smaller interval would be desirable. The introduction of dummy variables for three year intervals does not change the results. 


\section{$3.2 \quad$ Endogeneity issues}

The main problem that arises when estimating the impact of parental education on child mortality is its potential endogeneity. Having a high level of education might reflect some innate ability which might translate into a higher ability to take care of children and higher ability at school. Typically, someone processing information better and/or faster might be more successful in school and more able to understand and remember the mechanisms involved in the transmission of infections for example. Ability is not observed and will positively affect the level of education and the survival probability of children, leading to an overestimation of the effect of education.

In addition, parents who enjoy better health usually have children with good health. If parents' health is better now, it is likely that it was also good when they were children which might mean fewer school days lost due to illnesses. This factor is particularly relevant to rural Madagascar since children often have to walk long distances to get to school. Furthermore, when at school, healthier parents are more likely to have been more attentive than those in poor health. The better school attendance and greater attention in school of healthier parents could have resulted in their enjoying more years of schooling (see Currie and Vogl, 2012 for a review of child health and long term outcomes in developing countries). Maternal health is unobserved and positively correlated with both her education and the health of her children with the result that estimates of maternal education will be biased upwards.

Higher education might also reflect heterogeneity of time preferences. Individuals might have a lower preference for the present which makes their current costs relatively lower with respect to future benefits. They will be more likely to study for longer since the relative costs of schooling and the future benefits from education are lower for this group. These preferences are related also to greater investment in health inputs: vaccination which 
has long term benefits is a less attractive option for individuals focused on the present. Generally people living longer, most likely healthier people, simply have more incentive to invest in the future. They may invest more in their own health inputs which will also result in healthier children which will decrease their likelihood of dying.

Ultimately, all the sources of bias may overestimate the true effect of maternal education. One way to tackle the likely endogeneity issue is to use instrumental variables.

\subsection{Instruments}

The set of instrumental variables includes dummy variables for whether or not the parents lived near a primary school, a middle school or a high school when they were ten years old. These variables directly affect the amount of education received by parents. In addition, they provide variations over the full support of education. Because parents were of different ages at the time of the survey, they were not aged ten at the same point in time. As a result the instruments are varying across locations and across time ${ }^{15}$.

One argument against the use of these instruments is that the availability of schools (new school opening) could be linked to the availability of a health care center or alternatively that new health care centers were built based on the availability of schools. If so, school availability will proxy for availability of a health care center which a priori increases health regardless of education level. A dummy variable for whether or not parents lived in the proximity of a health center when they were ten years old is included in the questionnaire and table 18 in the appendix shows that living close to any of the school infrastructure is positively correlated to the probability of living proximate to a health care center. Thus, whenever these instruments are employed, health care center presence is added as a control

variable. Also, since community fixed-effects are introduced, we control for the availability

\footnotetext{
${ }^{15}$ Table 17 in the appendix shows within standard deviations (time variation) and between standard deviations (geographical variation) for all the instruments.
} 
of a current health care center.

There might be concern over the ability of parents to recall the availability of infrastructure. Since whether there was a school or not does not require additional detail, it is unlikely that it will have a significant effect (see Beckett et al., 2001). To confirm that it is not an issue, other infrastructure-based instruments were built for non migrants ${ }^{16}$. However to the extent that fixed effects are used in addition to restricting the sample to non migrants, instruments were found not to be powerful enough (unlike when both migrants and non migrants are included $)^{17}$. Remembering whether there was a school or not might not be as neutral as remembering another event. It is possible that when less educated women are asked about their education level, they begin to ex post rationalize on their lower levels of education by stating that schools were not available. Infrastructure questions were asked before questions on the level of education. They might however have already ex post rationalize their lower levels of education with lower availability of school infrastructure. Student tests of same mean for reporting the probability that there was a school for women who did not migrate from the same community and similar age never reject that means are identical between educated and less educated women ${ }^{18}$. Means were however higher for educated women. To the extent that living in the proximity of a school infrastructure does not necessarily mean that the infrastructure was exactly within the legal boundaries of the commune this is to be expected. Moreover the same kind of tests were run for health infrastructure which showed the same patterns, thereby casting doubt

\footnotetext{
${ }^{16}$ Only a fifth of people have migrated.

${ }^{17}$ The intra and inter variance was computed for all instruments and are provided in the appendix, table 17. Within standard deviation refers to the time variation of the instruments and between standard deviation to the geographical variation of the instruments, captured by the use of fixed effects. All infrastructure variables have a higher time variation than geographical variation except for high schools. All standard deviations seem to be high enough and the results for the instrumentation in the next section will prove so.

${ }^{18}$ Note that running regressions of the probability to report that there was an infrastructure on women who did not migrate with community fixed effects and controlling for age would necessarily show that educated women are more likely to report schooling infrastructure. The same goes if we aggregate all communities.
} 
on ex post rationalization.

Another concern relates to grandparents' location decisions. The parents of those parents who might have favored school might have been more likely to settle in a location where schools were available. Most households (80\%) have never moved, and among those who did, $70 \%$ were from a rural area (or went to a rural area and came back ${ }^{19}$ ) which casts doubt on education being a motive for migration. One question relates to reasons for migrating and only $2 \%$ state that the decision was school related. Location's decision of the grand parents might not be completely reflected in these statistics, however they do shed some light regarding migration patterns and location decisions of rural households seems not to be related to schooling.

The instrument variables were collected based on individuals aged over 18 years. Note that although this excludes current young mothers, it still includes mothers who had their children at a young age; therefore, the effect of teen pregnancies is still accounted for. The collection was further restricted to parents, defined as individuals living with at least one under 21 year child. That is, if the first and only child so far has died, instruments are not available. To circumvent the issue, we focus on women who gave at least two births ${ }^{20}$. It would be very uncommon in Madagascar to have only one birth (the total fertility rate was 5 in 2005). Since their fertility is censored we cannot really estimate the average number of children per mother in our database. Yet we can at least look at mother's number of siblings. The probability that the mother is a lonely child is $3.5 \%$ and it is not linked with her mother's level of education. This raises the more general problem of missing values for the instrumental variables. Provided that both groups are homogeneous, this should not

\footnotetext{
${ }^{19}$ The database does not distinguish individuals that come from another area and migrated to the current area from individuals originally from the current area, migrated and came back. It is possible that migration takes place after they finished schooling.

${ }^{20}$ There were five women who had exactly two live births and two child deaths and who are therefore still excluded
} 
be a major issue. The results of the student t-test for two-sample comparison are reported in tables 15. There are no statistically significant differences in any of the variables studied at the $10 \%$ level $^{21}$.

Besides the sample restriction for instruments, information on number of births or offsprings' survival is available only for women who answered themselves to the health module. This may lead to a selection bias if the presence of a woman in the household during the interview is not random. The results for a comparison of education, household composition, wealth and employment are presented in table 16. The sample of women aged 15 to 49 years who responded to these questions is examined and compared with the general sample of women aged 15 to 49 years. The two samples have comparable means and twomean comparison student t-tests indicate that the two samples are mostly comparable. The few divergences are in the probability of being currently enrolled in school which is lower for the left subsample. This is probably a sign that some women were at school at the time of the interview which is consistent with the slight age differences. Note that education measured in years or levels attained does not differ between the two samples. Thus, it is fair to argue that in terms of observable characteristics the sample is representative of the population surveyed.

\footnotetext{
${ }^{21}$ If we were to focus on the subsample of ever mothers (as opposed to the current sample of mothers who gave birth at least two births), there would be no difference for most of the variables but for age since women for which instruments are available are necessarily above 18. These women also have more children which might be a problem for the probability (not the ratio), however once looking at over 18 mothers, the means of the two mortality outcomes are not statistically different from the means obtained on the subsample with instruments.
} 


\section{Assessing the causal effect of education}

\subsection{Instrumentation}

Here we present the results of the instrumentation. Since community fixed effects are included and $80 \%$ of households have not migrated, there might be some concern that the instruments are not sufficiently powerful to explain schooling decisions. Table 6 column 1 shows the results of the regression for maternal level of schooling on school supply when the individual was aged ten. All three variables, primary school, middle school and high school availability have the expected positive and significant sign. The F statistic is high enough therefore there should be no concern over weak instruments.

To demonstrate further how well the instruments perform, table 6 columns 2 to 5 present the results of the regressions for each level of schooling on the instruments. Column 2 represents "primary school started" that is having attended school at any time; column 3 is completing primary school; column 4 is the regression results for having started middle school and column 5 represents any level of education above or equal to completion of middle school. The results show that infrastructure availability captures both access to school and the probability to complete a school level. The likelihood of completing one level of schooling is higher if there is an opportunity to enroll for the next level. These results suggest that the infrastructure variables are good predictors of education. Dumas and Lambert (2010) exploit the same strategy in Senegal and find that the instruments are valid $^{22}$. Regressing each level of education on the availability of a primary school, a middle school and a high school respectively show the same patterns as discussed above. Adding the number of children as a control (required for the ratio outcome) does not change the

\footnotetext{
${ }^{22}$ They use questions on infrastructure availability as a first set of instruments and primogeniture according to gender for the second set. Their model showed that maternal education did not need to be instrumented but father education was instrumented. The EIFID 2006 survey also has questions on being the first born however they were not good enough to run similar tests or use them for the instrumentation.
} 
results.

Since it could be argued that the instruments tend to predict the level of education "too" well, it should be noted that there is still room for decision making. The linear regression of the probability to report schooling type on age, ethnicity, education and with area fixed effects for women who did not migrate indicates that about half of the variation is unexplained by the model.

\subsection{Gross effect of education on mortality}

Table 7 panel A shows the results for the "gross" education effect. The control variables likely to be influenced by education are excluded. The regressions are run for mothers not children because information on mortality is at the level of the mother. Accordingly, when more than one death occurred, age and year of death cannot be attributed to the corresponding child ${ }^{23}$. Only ethnicity dummies, mother's age and mother's education are included in the regression. Here the interest is on assessing whether mother's education has a causal effect. The first column presents the results for the effect of maternal education on under five year mortality based on the sample of women who had at least two live births. The next regression is on the subsample available for the instrumental variables. Column 3 additionally controls for the availability of a health care center when the mother was aged ten. Column 4 presents the effect of education after instrumentation (shown in table 6, column 1).

The regressions in columns 1 to 3 panel A all point to a negative and significant effect of maternal education on child mortality. The subsample left for the instrumentation has a very similar effect of education and adding health care centers in column 3 do no significantly alter the effect of education either. Column 4 corresponds to the instrumented

\footnotetext{
${ }^{23}$ Even when a single death occurred, age at death was only given in categories (0-1 year, $1-2$ or $2-5$ years) and only for deaths occuring in the previous five years.
} 
regressions. The F statistics correspond to the hypothesis that the instruments are jointly zero in the regression of education. The corresponding p-value is 0.00 and as the F statistics is above 10, one should not worry about weak instruments. The coefficient of maternal education is no longer significant after instrumentation. We now look closely at whether instrumentation is needed. The p-value ${ }^{24}$ in the last column represents the probability that maternal education is exogenous. It corresponds to the "regression-based endogeneity test" where the residuals of the instrumentation are introduced with the potentially endogenous variable. The Student test on the coefficient of the residual is the reported p-value. If it is below $10 \%$ exogeneity might become a problem, below $5 \%$ exogeneity is usually rejected. The test of exogeneity of education indicates a probability of $90 \%$ that maternal education is exogenous (a Hausman test also fails to reject exogeneity). As the model is overidentified, the Sargan-Hansen test is run and the corresponding p-value is well above $10 \%$ strengthening confidence in the validity of the instruments. Comparing the regressions before and after instrumentation, it should be said that the coefficients for mother's education do not statistically differ (at the $10 \%$ level at least). Also with the prediction from the first stage, standard errors have been multiplied by almost five and to that extent the effect of education must be particularly strong to be captured by the instrumented regression.

Table 7 panel B presents the results for the same exercise applied to the second mortality variable, the ratio of children who died to the total number of the mother's childbirths ${ }^{25}$. The observations are identical to those made for the previous health outcome: mother's education has a significant and negative impact on the ratio of children who died. The instrumented coefficient for mother's education is not significant. The F statistic is large

\footnotetext{
${ }^{24} \mathrm{p}$-value (exogeneity) in the tables

${ }^{25}$ Because the coefficients are very small, the ratio was multiplied by 100 ; thus it is in fact a percentage although we refer to it as a ratio.
} 
enough and the Sargan Hansen test is $28.7 \%$ so that we can be confident in our instruments. The probability that education is exogenous is as high as $65.1 \%$. It seems that the "omitted" variables for preferences, greater ability or health do not strongly correlate with our two mortality measures (they might do with child health outcomes) ${ }^{26}$.

Since exogeneity can not be rejected, we employ the standard linear regression and favor the specification in column 2 for panels A and B (that is we do not instrument therefore we do not control for health care centers). The effects on both mortality outcomes are negative and significant at 1\%. Each year of education decreases the likelihood of experiencing a child death by almost one percentage point $(-0.0085 * 100=0.85 \%)$. Comparing a woman with no education with a woman who finished middle school, the educated mother has at least 7.5 percentage points less chance of experiencing child death. These figures are very high and show how much maternal education matters. For the ratio, interpretation is more complex. If education increases by one year, the ratio will decrease by 0.003 (recall that the ratio is multiplied by 100).

We do not report estimations with father's education as it never proved significant. The analysis was limited to partner's information instead of father's because information on mortality is given by mothers. Only mothers with a partner ${ }^{27}$ were analyzed and therefore interpretation should be cautious. When introduced, mother's education still had an effect on that subsample however father's education did not ${ }^{28}$. Since father's education has no

\footnotetext{
${ }^{26}$ Maïga (2011) also finds that the exogeneity of maternal education cannot be rejected when investigating height-for-age (exogeneity is however rejected for weight-for-height). Dumas and Lambert (2011) study the impact of parental education on offsprings' education and do not reject the exogeneity of mother's education (though they do for father's education). Previously cited studies on SSA did not explicitly report the results of the exogeneity test.

${ }^{27}$ The database does not provide information on marital status. In Madagascar, $70 \%$ of mothers are married, $7 \%$ live with a partner and only $4 \%$ are single (the other $19 \%$ are separated, divorced or widowed). For women who gave birth less than five years before the survey, $70 \%$ have a partner (married or not), 20\% are separated and $10 \%$ are single.

${ }^{28}$ This holds whether we control for wealth, mother's education, number of children or none of these variables. Regressions and descriptive statistics are available upon request. As age of the father and
} 
significant effect, it is not included in the following estimations ${ }^{29}$.

\section{Discussion of the mechanisms}

Mother's education has a positive impact on child survival; however, the validity of the mechanisms described earlier needs to be demonstrated for Madagascar. We ran a decomposition exercise introducing the variables that might be channels through which education impacts on child health. The impact of these variables on child health on their own as well as through the coefficient of education are examined. Table 9 reports the effect of education on the probability of losing a child and table 10 presents the results for the ratio of the number of children who died to the total number of births.

Looking at how the introduction of new covariates affects the effect of education in table 9, one can see that wealth accounts for a third of the effect of mother's education on the probability to lose a child. Mother's education remains significant at the $10 \%$ threshold. Having no toilet significantly increases the probability of a child death although it does not seem to be related to education. When the number of children is introduced this barely reduces the effect of education which still remains significant and negative. The introduction of all the pathways seems to capture all of the effect of maternal education at least for the binary outcome ${ }^{30}$.

Table 10 shows the effect for the ratio and the patterns are quite similar. Education significantly decreases the mortality ratio and wealth accounts for about a third of that effect. Not having access to toilet is a strong predictor of mortality, and again, does

the mother were always introduced, we could have captured a household composition however different specifications for spouses' age difference were introduced and were not significant.

${ }^{29}$ Instrumenting father's education with schooling infrastructures in his childhood showed no significant endogeneity. Instrumentation of both mother's and father's education was not possible since Shea's (1997) partial $\mathrm{R}$ was lower than $5 \%$ for both variables.

${ }^{30}$ This result however does not hold to alternative measures of education such as the measure of education in levels where education still remains significant at the $10 \%$ threshold. 
not seem to be related to maternal schooling. Introducing all the variables, the effect of education remains strong and significant. Tables 9 and 10 do not seem to indicate that educated mothers have better hygiene practises as proxied by waste disposal methods (litter away) $)^{31}$. Once controlling for wealth ${ }^{32}$, the waste disposal method matters and not throwing waste away reduces the probability of experiencing child death. We next examine care during and after pregnancy.

Information on pre/postnatal care and birth delivery are available only for women who were pregnant in the previous five years. Since these mothers are younger, the population used for the estimation is also younger. For this reason, the basic regressions with the gross effect of education and its effect when wealth is included are provided. Table 11 presents the effects of mother's education on under five mortality. The first column shows the "gross effect" of education on the sample of mothers pregnant in the previous five years. Columns 1 to 6 indicate that pre and post natal care do not have a significant impact and that whatever small impact they have (note that their coefficients are still in the right direction) does not seem to linked to education. Tetanus vaccination has a very strong impact and is consistent with the conditions in which mothers give birth. Many births occur at home and/or with a "traditional midwife", and the extent to which houses in rural area can provide hygienic conditions for deliveries is small. UNICEF reports that: "A newborn can be infected with tetanus due to unhygienic birthing practices, such as cutting the umbilical cord with unsterilized instruments or treating it with contaminated dressings." If this occurs, the child will die within the first week or month after its birth. Tetanus vaccination does not seem to be a mechanism which is lined to education. Since it causes death in the first week or month, it could be that education simply does not

\footnotetext{
${ }^{31}$ litter away takes the value 1 if waste is thrown away and 0 if it is burnt, burried or taken away.

${ }^{32}$ Results are not reported but simply controlling for wealth makes waste disposal methods become significant. Tables 9 and 10 simply show that after the inclusion of all mechanisms (including wealth), waste disposal method is significant.
} 
explain neonatal death. Basu and Stephenson (2005) find that even low levels of maternal education are beneficial for several indicators of health/survival measures except neonatal mortality where no effect was found. The present data do not allow exclusion of neonatal deaths.

Note that other variables discussed in the description of the data, namely where the mother received prenatal care if any, whether she took iron tablets, where the delivery took place and whether the delivery was attended by qualified medical staff (doctor or midwife), are not associated with either a drop in the effect of education or a significant effect, and are not reported here. No interaction between education and one of the variables proxying the mechanisms were significant. Vaccination was investigated but no significant effect was found. If educated mothers are more likely to have their children vaccinated, and if education has spillover effects, then with the inclusion of community fixed effects it is difficult to find an effect of education on vaccination. That explanation is consistent with Aslam and Kingdon's (2012) study in Pakistan where after the introduction of community fixed effects, mother's education no longer impacts immunization.

Regarding the lack of effect of health care use, it should be emphasized that local fixed effects were introduced, so that this result may be due in part to the (necessary) estimation strategy. They correspond to communities which by definition are quite small areas. To that extent, a share of the health infrastructure effect is captured. However, all variables proxying for health care use have higher within than between standard deviations as shown in table 17; thus, the share captured by fixed effects will be modest. Using larger areas such as regions also did not lead to significant effects. As none of the interactions (referred to earlier but not reported) between health care and education are significant, it can still be said that the effect of mother's schooling on child survival is a priori not being channeled through higher use of pre and postnatal care. Though it cannot be inferred that 
the pre and/or postnatal care variables have no effect on the probability of child survival, it should be highlighted that the quality of health care is usually poorer in rural areas. Another possible explanation is in the potential positive externalities at the community level that some of the health care variables may have. For example if some women inside the community are assisted by trained staff at birth, these women or the staff may spread information about best practices regarding child delivery that will improve the likelihood of survival at the community level, even for mothers not assisted by trained professional at birth. Tetanus vaccination protects only the mother and the child and this protection has no positive externalities on other women of the community ${ }^{33}$. Therefore positive externalities may explain why pre and post natal care have no significant impact on the mother who received them with community fixed effects. It is also possible that peri natal care might play a stronger role in child health than child survival in a country where many deaths seem to be the result of tetanus infections.

All the results presented are robust to alternative measures of education such as the level of schooling (primary/secondary levels completed or not completed). Using the sample of mothers with at least one birth, results are similar though the effect of education is weaker (consistent with omission of mothers whose first and only child $\operatorname{died}^{34}$ ). Results are also robust to the exclusion of women with no child over five nor deceased child ${ }^{35}$. Using a logit model leads to similar results. To the extent that instrumental variables are not available

\footnotetext{
${ }^{33}$ Actually it could if it would somehow be a proxy for other types of care. However there is no reason to believe that a mother's tetanus vaccination (to protect her baby at birth) would proxy for other types of care more than the other variables I have used (such as receiving vitamin A supplements or being assisted by a trained professional at birth).

${ }^{34}$ The instrumentation and exogeneity tests are similar and mechanisms regarding deliveries in the last five years show similar patterns. Results for the general mechanisms show weaker effect of education.

${ }^{35}$ Excluding them avoids considering that they have experienced no child's death when in fact we do not know whether their child will survive to age five. However, excluding them would be non random since it would remove women who had healthy recent births whereas women who recently lost a child cannot be removed (the year of child death is not known). To that extent it is important to strengthen that results whether they are included or not (and this holds whether our main sample is composed of mothers with at least one live birth or mothers with at least two live births).
} 
for all women, an indicator variable for whether the instruments are available was created. The results are similar when these women are included ${ }^{36}$.

\section{Conclusion}

This paper questioned whether maternal education has a causal impact on child mortality. The original dataset, encompassing responses to questions on infrastructure availability in childhood suggests that maternal education's exogeneity cannot be rejected. Mechanisms were examined through the responses to a detailed survey module asking for information on prenatal care, birth delivery conditions and postnatal care. We found that mother's education has a strong and negative impact on child mortality. Each additional year of schooling decreases the probability of losing one under five year old child by $1 \%$. Compared to an uneducated mother, women who finished primary school have $5 \%$ chance less to experience a child loss. Wealth is an important predictor and accounts for approximately a third of the effect of education. Having any kind of sanitation facilities significantly reduces child mortality regardless of mother's education. With the exception of tetanus vaccination, health care variables have no significant effect. It would seem to be the result of the introduction of community fixed effects and the high rates of neonatal mortality due mainly to tetanus and which no health care variable except tetanus vaccination can alleviate. To conclude, the results of our study reinforce the idea that education should be a priority since it benefits both the educated individuals and the next generation. Since the effect of father's education disappears once wealth or mother's education is accounted for, improving access to education while closing the gender gap would appear to offer the most potential.

\footnotetext{
${ }^{36}$ The dummy for whether the instruments are available is not significant in the main regressions (probability to lose a child and the ratio of children lost) which is consistent with the fact that results do not differ.
} 


\section{References}

[1] Agüero, Jorge M. and Bharadwaj, Prashant. Do the More Educated Know More about Health? Evidence from Schooling and HIV Knowledge in Zimbabwe. Economic Development and Cultural Change, 62(3):489 - 517, 2014.

[2] Monazza Aslam and Geeta Gandhi Kingdon. Parental Education and Child Health: Understanding the Pathways of Impact in Pakistan. World Development, 40(10):2014$2032,2012$.

[3] Alaka Malwade Basu and Rob Stephenson. Low levels of maternal education and the proximate determinants of childhood mortality: a little learning is not a dangerous thing. Social Science $\&$ Medicine, 60(9):2011-2023, May 2005.

[4] Megan Beckett, Julie Da Vanzo, Narayan Sastry, Constantijn Panis, and Christine Peterson. The quality of retrospective data: An examination of long-term recall in a developing country. Journal of Human Resources, pages 593-625, 2001.

[5] Jere R. Behrman and Barbara L. Wolfe. How does mother's schooling affect family health, nutrition, medical care usage, and household sanitation? Journal of Econometrics, 36(1):185-204, 1987.

[6] J. Ties Boerma, A. Elisabeth Sommerfelt, and George T. Bicego. Child Anthropometry in Cross-sectional Surveys in Developing Countries: An Assessment of the Survivor Bias. American Journal of Epidemiology, 135(4):438-449, February 1992.

[7] Lucia Breierova and Esther Duflo. The Impact of Education on Fertility and Child Mortality: Do Fathers Really Matter Less Than Mothers? NBER Working Papers 10513, National Bureau of Economic Research, Inc, May 2004. 
[8] John C. Caldwell. Education as a factor in mortality decline an examination of Nigerian data. Population Studies, pages 395-413, 1979.

[9] Yuyu Chen and Hongbin Li. Mother's education and child health: Is there a nurturing effect? Journal of Health Economics, 28(2):413-426, March 2009.

[10] Shin-Yi Chou, Jin-Tan Liu, Michael Grossman, and Ted Joyce. Parental Education and Child Health: Evidence from a Natural Experiment in Taiwan. American Economic Journal: Applied Economics, 2(1):33-61, January 2010.

[11] Janet Currie and Enrico Moretti. Mother's education and the intergenerational transmission of human capital: Evidence from college openings. The Quarterly Journal of Economics, 118(4):1495-1532, 2003.

[12] Janet Currie and Tom Vogl. Early-Life Health and Adult Circumstance in Developing Countries. Annual Review of Economics, 5(1):1-36, 052013.

[13] Orla Doyle, Colm Harmon, and Ian Walker. The Impact of Parental Income and Education on Child Health. Further Evidence for England. Working Papers 200706, Geary Institute, University College Dublin, February 2007.

[14] Christelle Dumas and Sylvie Lambert. Educational Achievement and Socio-economic Background: Causality and Mechanisms in Senegal. Journal of African Economies, 20(1):1-26, January 2011.

[15] Deon Filmer and Lant Pritchett. Estimating wealth effects without expenditure dataor tears: an application to educational enrollments in states of India. Demography, 38(1):115-132, February 2001.

[16] Jocelyn E. Finlay, Emre Özaltin, and David Canning. The association of maternal age with infant mortality, child anthropometric failure, diarrhoea and anaemia for first 
births: evidence from 55 low- and middle-income countries. BMJ Open, 1(2), January 2011.

[17] Paul Glewwe. Why Does Mother's Schooling Raise Child Health in Developing Countries? Evidence from Morocco. The Journal of Human Resources, 34(1), January 1999.

[18] Peter Glick, Christopher Handy, and David Sahn. Schooling, marriage and age of first birth in madagascar. IZA Discussion Papers 8795, Institute for the Study of Labor (IZA), 2015.

[19] Karen A Grépin and Prashant Bharadwaj. Maternal education and child mortality in Zimbabwe. Journal of Health Economics, 44:97-117, 2015.

[20] Sudhanshu Handa. Maternal education and child height. Economic Development and Cultural Change, 47(2):421-439, 1999.

[21] John Hobcraft. Women's education, child welfare and child survival: a review of the evidence. Health Transition Review, pages 159-175, 1993.

[22] Eugenie W. H. Maïga. The Impact of Mother's Education on Child Health and Nutrition in Developing Countries: Evidence from a Natural Experiment in Burkina Faso. 2011.

[23] Nelly Rakoto-Tiana. Confiage et scolarisation des enfants en milieu rural à Madagascar. Working Papers DT/2012/01, DIAL (Développement, Institutions et Mondialisation), March 2012.

[24] Amartya Sen. Mortality as an indicator of economic success and failure. The Economic Journal, 108(446):1-25, 1998. 
[25] John Shea. Instrument relevance in multivariate linear models: A simple measure. Review of Economics and Statistics, 79(2):348-352, 1997.

[26] Duncan Thomas, John Strauss, and Maria-Helena Henriques. How does mother's education affect child height? Journal of Human Resources, pages 183-211, 1991. 
Table 1: Distribution of the level of education for adults aged 18 to 55 years old, disaggregated by gender

\begin{tabular}{lrrrrrr}
\hline \multirow{2}{*}{ Level of education } & \multicolumn{2}{c}{ Women } & \multicolumn{2}{c}{ Men } & \multicolumn{2}{c}{ Total } \\
& Freq. & Percent & Freq. & Percent & Freq. & Percent \\
\hline No education & 1,109 & 24.05 & 836 & 18.87 & 1,945 & 21.51 \\
Primary school, incomplete & 1,706 & 36.99 & 1,645 & 37.13 & 3,351 & 37.06 \\
Primary school, completed & 856 & 18.56 & 822 & 18.56 & 1,678 & 18.56 \\
Middle school, incomplete & 499 & 10.82 & 444 & 10.02 & 943 & 10.43 \\
Middle school, completed & 442 & 9.58 & 683 & 15.42 & 1,125 & 12.44 \\
Total & 4,612 & 100 & 4,430 & 100 & 9,042 & 100 \\
\hline
\end{tabular}


Table 2: Number of years of education for adults aged 18 to 55 years old, disaggregated by gender

\begin{tabular}{ccccccc}
\hline Years of & \multicolumn{2}{c}{ Women } & \multicolumn{2}{c}{ Men } & \multicolumn{2}{c}{ Total } \\
education & $\mathrm{N}$ & $\%$ & $\mathrm{~N}$ & $\%$ & Total & $\%$ \\
\hline 0 & 1,125 & 24.39 & 854 & 19.28 & 1,979 & 21.89 \\
1 & 162 & 3.51 & 149 & 3.36 & 311 & 3.44 \\
2 & 439 & 9.52 & 382 & 8.62 & 821 & 9.08 \\
3 & 612 & 13.27 & 636 & 14.36 & 1,248 & 13.80 \\
4 & 473 & 10.26 & 453 & 10.23 & 926 & 10.24 \\
5 & 863 & 18.71 & 827 & 18.67 & 1,690 & 18.69 \\
6 & 131 & 2.84 & 108 & 2.44 & 239 & 2.64 \\
7 & 188 & 4.08 & 162 & 3.66 & 350 & 3.87 \\
8 & 179 & 3.88 & 182 & 4.11 & 361 & 3.99 \\
9 & 269 & 5.83 & 377 & 8.51 & 646 & 7.14 \\
10 & 43 & 0.93 & 61 & 1.38 & 104 & 1.15 \\
11 & 39 & 0.85 & 67 & 1.51 & 106 & 1.17 \\
12 & 77 & 1.67 & 153 & 3.45 & 230 & 2.54 \\
13 & 0 & 0.00 & 1 & 0.02 & 1 & 0.01 \\
14 & 8 & 0.17 & 9 & 0.20 & 17 & 0.19 \\
15 & 3 & 0.07 & 3 & 0.07 & 6 & 0.07 \\
16 & 1 & 0.02 & 3 & 0.07 & 4 & 0.04 \\
17 & 0 & 0.00 & 1 & 0.02 & 1 & 0.01 \\
20 & 0 & 0.00 & 2 & 0.05 & 2 & 0.02 \\
Total & 4,612 & 100 & 4,430 & 100 & 9,042 & 100 \\
\hline
\end{tabular}

Table 3: Locations where women gave birth and obtained prenatal care

\begin{tabular}{lrrrr}
\hline & \multicolumn{2}{c}{ Birth place } & \multicolumn{2}{c}{ Prenatal care } \\
Location & Obs. & Percentage & Obs. & Percentage \\
\hline Hospital & 50 & 3.09 & 52 & 3.55 \\
CSB 1 & 118 & 7.28 & 216 & 14.7 \\
CSB 2 & 716 & 44.2 & 1105 & 75.4 \\
Private sector & 35 & 2.16 & 57 & 3.89 \\
Traditional & 170 & 10.5 & 36 & 2.46 \\
Home & 531 & 32.8 & 0 & 0 \\
Total & 1620 & 100 & 1466 & 100 \\
\hline
\end{tabular}


Table 4: Number of children lost and ratio of deaths by maternal level of education

\begin{tabular}{ccccccccc}
\hline & \multicolumn{2}{c}{ No } & \multicolumn{2}{c}{ Primary school } & \multicolumn{2}{c}{ Middle school } & \multicolumn{2}{c}{ Total } \\
$\mathrm{N}$ & education & incomplete & completed & incomplete & completed & total & freq. & p-value \\
\hline 0 & 72.1 & 73.5 & 76.8 & 74.7 & 78.5 & 74.4 & 2020 & 0.12 \\
1 & 15.3 & 16.7 & 16.6 & 18.8 & 14.6 & 16.4 & 444 & 0.38 \\
2 & 9.24 & 7.36 & 5.42 & 4.79 & 5 & 6.93 & 188 & 0.01 \\
$>2$ & 3.39 & 2.45 & 1.12 & 1.71 & 1.92 & 2.28 & 62 & 0.03 \\
Total & 100 & 100 & 100 & 100 & 100 & 100 & 2714 &. \\
\hline Ratio, mean & 6.98 & 6.71 & 5.83 & 6.84 & 5.99 & 6.55 & 2714 & 0.33 \\
Ratio, std dev & 12.7 & 13.3 & 12.2 & 13.6 & 13.4 & 13.0 &. &. \\
\hline
\end{tabular}




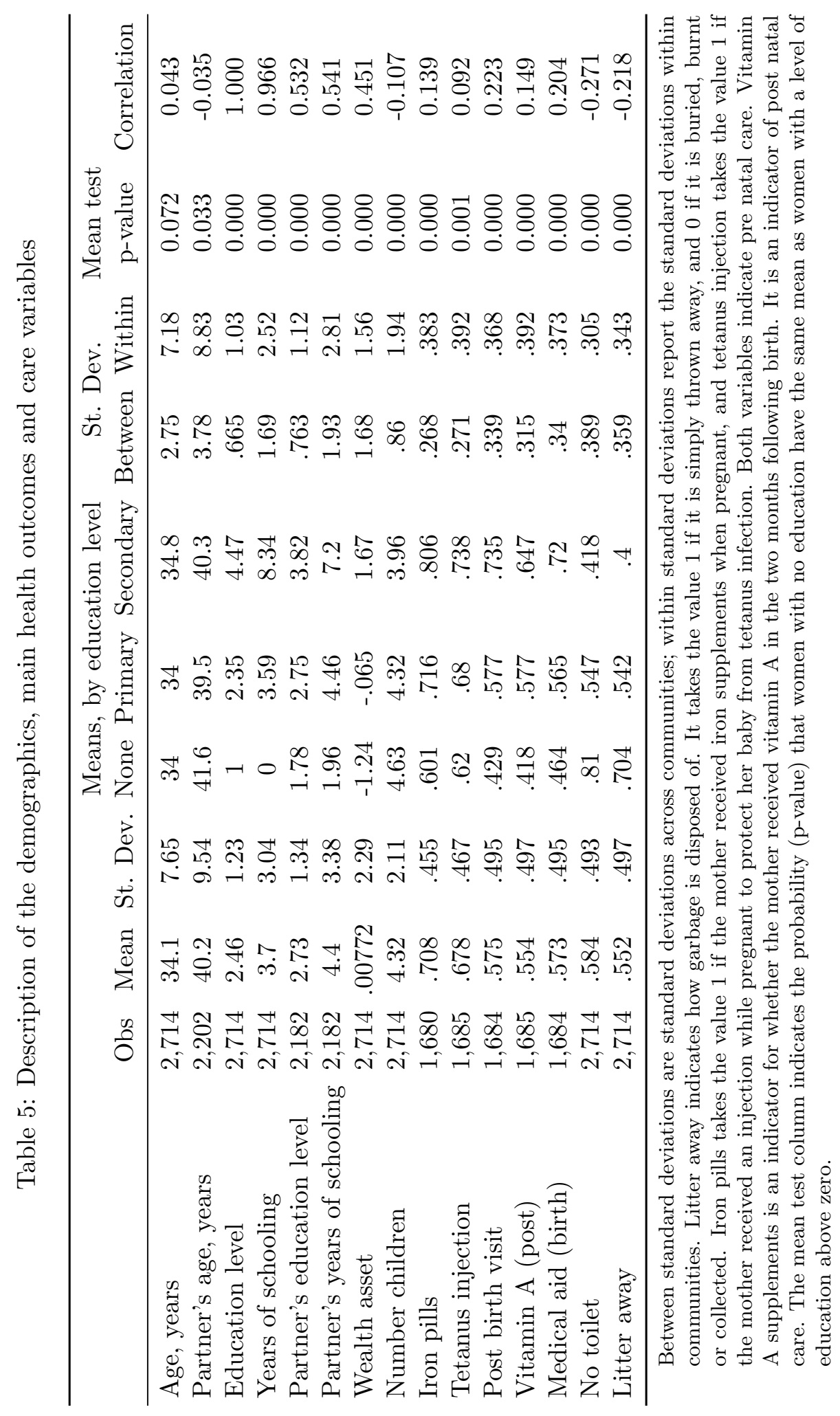


Table 6: Instrumentation of maternal education: OLS (first stage) regression of years of schooling and schooling levels

\begin{tabular}{|c|c|c|c|c|c|}
\hline & $\begin{array}{c}(1) \\
\text { education } \\
\text { (in years) }\end{array}$ & $\begin{array}{c}(2) \\
\text { prim started } \\
\text { (binary) }\end{array}$ & $\begin{array}{c}(3) \\
\text { prim compl. } \\
\text { (binary) }\end{array}$ & $\begin{array}{c}(4) \\
\text { mid.started } \\
\text { (binary) }\end{array}$ & $\begin{array}{c}(5) \\
\text { mid.sch.+ } \\
\text { (binary) }\end{array}$ \\
\hline Primary school & $\begin{array}{l}1.014^{* * *} \\
(0.175)\end{array}$ & $\begin{array}{l}0.208^{* * *} \\
(0.030)\end{array}$ & $\begin{array}{l}0.106^{* * *} \\
(0.029)\end{array}$ & $\begin{array}{l}0.032+ \\
(0.020)\end{array}$ & $\begin{array}{l}0.029^{* *} \\
(0.014)\end{array}$ \\
\hline Middle school & $\begin{array}{l}0.953^{* * *} \\
(0.194)\end{array}$ & $\begin{array}{l}0.009 \\
(0.021)\end{array}$ & $\begin{array}{l}0.116^{* * *} \\
(0.034)\end{array}$ & $\begin{array}{l}0.145^{* * *} \\
(0.030)\end{array}$ & $\begin{array}{l}0.093^{* * *} * \\
(0.023)\end{array}$ \\
\hline High school & $\begin{array}{l}1.368^{* * *} \\
(0.359)\end{array}$ & $\begin{array}{l}0.028 \\
(0.028)\end{array}$ & $\begin{array}{l}0.177 * * * \\
(0.042)\end{array}$ & $\begin{array}{l}0.187 * * * \\
(0.056)\end{array}$ & $\begin{array}{l}0.144^{* * *} \\
(0.046)\end{array}$ \\
\hline Health center & $\begin{array}{l}0.367^{* *} \\
(0.154)\end{array}$ & $\begin{array}{l}0.087^{* * * *} \\
(0.019)\end{array}$ & $\begin{array}{l}0.036 \\
(0.028)\end{array}$ & $\begin{array}{l}0.021 \\
(0.022)\end{array}$ & $\begin{array}{l}0.003 \\
(0.016)\end{array}$ \\
\hline F-stat & 32.8 & 16.4 & 22.2 & 20.8 & 15.1 \\
\hline P-value & 0.000 & 0.000 & 0.000 & 0.000 & 0.000 \\
\hline Observations & 2714 & 2714 & 2714 & 2714 & 2714 \\
\hline
\end{tabular}

$+\mathrm{p}<.13,{ }^{*} \mathrm{p}<.10,{ }^{* *} \mathrm{p}<.05,{ }^{* * *} \mathrm{p}<.01 ;$ standard errors in parentheses; mother's age in five year intervals, ethnic group and community fixed-effects (CFE) are included. The p-value indicates the probability that the coefficients for the instruments are all zero. 
Table 7: Linear regressions of child mortality on maternal education, with and witout instrumentation

\begin{tabular}{|c|c|c|c|c|c|c|c|c|}
\hline & \multicolumn{4}{|c|}{ A: Probability to have lost one child } & \multicolumn{4}{|c|}{ B: Ratio of dead children on total births } \\
\hline & (1) & (2) & $(3)$ & (4) & (1) & (2) & (3) & (4) \\
\hline & LPM & LPM & LPM & TSLS & OLS & OLS & OLS & TSLS \\
\hline Mother's education & $-0.010^{* * *}$ & $-0.009^{* * *}$ & $-0.009 * * *$ & -0.007 & $-0.352^{* * *}$ & $-0.303^{* * *}$ & $-0.288^{* * *}$ & -0.095 \\
\hline & $(0.003)$ & $(0.003)$ & $(0.003)$ & $(0.013)$ & $(0.099)$ & $(0.101)$ & $(0.105)$ & $(0.500)$ \\
\hline Health center & & & -0.013 & -0.015 & & & -0.604 & -0.788 \\
\hline & & & $(0.021)$ & $(0.023)$ & & & $(0.683)$ & $(0.820)$ \\
\hline Number children & & & & & $-1.287^{* * *}$ & $-1.015^{* * *}$ & $-1.020^{* * *}$ & $-0.982^{* * *}$ \\
\hline & & & & & $(0.193)$ & $(0.182)$ & $(0.182)$ & $(0.185)$ \\
\hline F-sta & & & & 32.8 & & & & 32.8 \\
\hline P-val & & & & 0.000 & & & & 0.000 \\
\hline Wu Hausman (p-value) & & & & 0.902 & & & & 0.651 \\
\hline Sargan Hansen (p-value) & & & & 0.556 & & & & 0.287 \\
\hline Instruments & no & no & no & yes & no & no & no & yes \\
\hline Observations & 2859 & 2714 & 2714 & 2714 & 2859 & 2714 & 2714 & 2714 \\
\hline
\end{tabular}

$+\mathrm{p}<.13,{ }^{*} \mathrm{p}<.10,{ }^{* *} \mathrm{p}<.05,{ }^{* * *} \mathrm{p}<.01 ;$ standard errors in parentheses; mother's age in five year intervals, ethnic groups and community fixed-effects (CFE) are included. Mother's education is measured by years of schooling. The p-value indicates the probability that mother's education is exogenous.

Table 8: Linear regressions of child mortality on maternal education

\begin{tabular}{lllll}
\hline & \multicolumn{2}{l}{ Probability child loss } & \multicolumn{2}{l}{ Ratio dead / ever born } \\
\hline Mother's education & $-0.008^{* * *}$ & $-0.009^{* * *}$ & $-0.200^{* *}$ & $-0.303^{* * *}$ \\
& $(0.003)$ & $(0.003)$ & $(0.093)$ & $(0.101)$ \\
Number children & & & $-0.741^{* * *}$ & $-1.015^{* * *}$ \\
& & & $(0.175)$ & $(0.182)$ \\
Observations & 2714 & 2714 & 2714 & 2714 \\
CFE & no & yes & no & yes \\
\hline
\end{tabular}

$+\mathrm{p}<.13,{ }^{*} \mathrm{p}<0.1, * * \mathrm{p}<0.05, * * * \mathrm{p}<0.01 ;$ standard errors are in parentheses; mother's age in five year intervals and ethnic group are included. Where indicated, Community Fixed-Effects (CFE) are included. Controls for the number of children are added only for the ratio outcome. 
Table 9: Effects of education and potential mechanisms on the probability to lose one child (linear probability model)

\begin{tabular}{|c|c|c|c|c|c|c|}
\hline & \multicolumn{6}{|c|}{ Probability to lose one under five (U5) child } \\
\hline & (1) & $(2)$ & $(3)$ & $(4)$ & $(5)$ & $(6)$ \\
\hline Mother's education & $\begin{array}{l}-0.009^{* * *} \\
(0.003)\end{array}$ & $\begin{array}{l}-0.008^{* *} \\
(0.003)\end{array}$ & $\begin{array}{c}-0.006^{*} \\
(0.003)\end{array}$ & $\begin{array}{l}-0.008^{* *} \\
(0.003)\end{array}$ & $\begin{array}{l}-0.010^{* * *} \\
(0.003)\end{array}$ & $\begin{array}{l}-0.005 \\
(0.003)\end{array}$ \\
\hline Number children & & $\begin{array}{l}0.018^{\text {*** }} \\
(0.005)\end{array}$ & & & & $\begin{array}{l}0.017^{* * *} \\
(0.005)\end{array}$ \\
\hline Wealth asset & & & $\begin{array}{l}-0.019 * * * \\
(0.006)\end{array}$ & & & $\begin{array}{l}-0.015^{* *} \\
(0.006)\end{array}$ \\
\hline No toilet & & & & $\begin{array}{l}0.087^{* * *} \\
(0.026)\end{array}$ & & $\begin{array}{l}0.067^{* *} \\
(0.028)\end{array}$ \\
\hline Litter away & & & & & $\begin{array}{l}-0.029 \\
(0.028)\end{array}$ & $\begin{array}{l}-0.044+ \\
(0.028)\end{array}$ \\
\hline Observations & 2714 & 2714 & 2714 & 2714 & 2714 & 2714 \\
\hline $\mathrm{CFE}$ & yes & yes & yes & yes & yes & yes \\
\hline
\end{tabular}

$+\mathrm{p}<.13,^{*} \mathrm{p}<0.1,{ }^{*} \mathrm{p}<0.05,{ }^{* * *} \mathrm{p}<0.01$; standard errors are in parentheses; mother's age in five year intervals, ethnic group and community fixed-effects (CFE) are included.

Table 10: Effects of education and potential mechanisms on the ratio of children who died on the total number of births the mother experienced (OLS)

\begin{tabular}{|c|c|c|c|c|c|c|}
\hline & \multicolumn{6}{|c|}{ Ratio of dead children on number of births } \\
\hline & (1) & $(2)$ & $(3)$ & (4) & $(5)$ & (6) \\
\hline \multirow[t]{2}{*}{ Mother's education } & $-0.210^{* *}$ & $-0.303^{* * *}$ & $-0.203^{* *}$ & $-0.271^{* * *}$ & $-0.315^{* * *}$ & $-0.221^{* *}$ \\
\hline & $(0.103)$ & $(0.101)$ & $(0.099)$ & $(0.101)$ & $(0.101)$ & $(0.098)$ \\
\hline \multirow[t]{2}{*}{ Number children } & & $-1.015^{* * *}$ & $-1.030^{* * *}$ & $-1.001^{* * *}$ & $-1.019^{* * *}$ & $-1.021^{* * *}$ \\
\hline & & $(0.182)$ & $(0.182)$ & $(0.180)$ & $(0.182)$ & $(0.180)$ \\
\hline \multirow[t]{2}{*}{ Wealth asset } & & & $-0.528^{* * *}$ & & & $-0.397^{*}$ \\
\hline & & & $(0.191)$ & & & $(0.213)$ \\
\hline \multirow[t]{2}{*}{ No toilet } & & & & $2.808^{* * *}$ & & $2.201^{* *}$ \\
\hline & & & & $(0.777)$ & & $(0.854)$ \\
\hline \multirow[t]{2}{*}{ Litter away } & & & & & -0.900 & $-1.399^{*}$ \\
\hline & & & & & $(0.765)$ & $(0.764)$ \\
\hline Observations & 2714 & 2714 & 2714 & 2714 & 2714 & 2714 \\
\hline
\end{tabular}

$+\mathrm{p}<.13,^{*} \mathrm{p}<0.1,{ }^{*} \mathrm{p}<0.05,{ }^{* * *} \mathrm{p}<0.01$; standard errors are in parentheses; mother's age in five year intervals, ethnic group and community fixed-effects (CFE) are included. 
Table 11: Probability to lose one under five year old child (linear probability model)

\begin{tabular}{|c|c|c|c|c|c|c|c|}
\hline & (1) & $\begin{array}{l}\text { Probab } \\
(2)\end{array}$ & $\begin{array}{l}\text { bility to los } \\
\text { (3) }\end{array}$ & e an under & $\begin{array}{l}\text { five year o } \\
\text { (5) }\end{array}$ & $\begin{array}{l}\text { old child } \\
\qquad(6)\end{array}$ & (7) \\
\hline Mother's education & $\begin{array}{l}-0.018^{* * *} \\
(0.005)\end{array}$ & $\begin{array}{l}-0.015^{* * *} \\
(0.005)\end{array}$ & $\begin{array}{l}-0.017^{* * *} \\
(0.005)\end{array}$ & $\begin{array}{l}-0.018^{* * *} \\
(0.005)\end{array}$ & $\begin{array}{l}-0.017^{* * *} \\
(0.005)\end{array}$ & $\begin{array}{l}-0.018^{* * *} \\
(0.005)\end{array}$ & $\begin{array}{l}-0.014^{* * *} \\
(0.005)\end{array}$ \\
\hline Wealth asset & & $\begin{array}{l}-0.016^{*} \\
(0.009)\end{array}$ & & & & & $\begin{array}{l}-0.014+ \\
(0.008)\end{array}$ \\
\hline Medical aid (birth) & & & $\begin{array}{l}-0.048 \\
(0.034)\end{array}$ & & & & $\begin{array}{l}-0.032 \\
(0.044)\end{array}$ \\
\hline Vitamin A (post) & & & & $\begin{array}{l}-0.025 \\
(0.031)\end{array}$ & & & $\begin{array}{l}-0.002 \\
(0.032)\end{array}$ \\
\hline Post birth visit & & & & & $\begin{array}{l}-0.034 \\
(0.032)\end{array}$ & & $\begin{array}{l}0.003 \\
(0.040)\end{array}$ \\
\hline Tetanus injection & & & & & & $\begin{array}{l}-0.057^{* *} \\
(0.028)\end{array}$ & $\begin{array}{l}-0.046+ \\
(0.028)\end{array}$ \\
\hline Observations & 1623 & 1623 & 1623 & 1623 & 1623 & 1623 & 1623 \\
\hline
\end{tabular}

$+\mathrm{p}<.13,{ }^{*} \mathrm{p}<0.1,{ }^{*} \mathrm{p}<0.05, * * * \mathrm{p}<0.01$; standard errors are in parentheses; mother's age in five year intervals, ethnic groups and community fixed-effects (CFE) are included. Postbirth visit takes the value 1 if the mother visited a doctor/midwife after giving birth. 
Table 12: Effects of education and potential pre/post birth mechanisms on the ratio of children who died (OLS)

\begin{tabular}{|c|c|c|c|c|c|c|c|}
\hline & \multicolumn{7}{|c|}{ Ratio of dead children on number of births } \\
\hline & $(1)$ & $(2)$ & $(3)$ & $(4)$ & $(5)$ & $(6)$ & $(7)$ \\
\hline Mother's education & $\begin{array}{l}-0.524^{* * *} \\
(0.145)\end{array}$ & $\begin{array}{l}-0.391^{* * *} \\
(0.141)\end{array}$ & $\begin{array}{l}-0.510^{\text {*** }} \\
(0.149)\end{array}$ & $\begin{array}{l}-0.519^{* * *} \\
(0.145)\end{array}$ & $\begin{array}{l}-0.511^{* * *} \\
(0.148)\end{array}$ & $\begin{array}{l}-0.516^{* * *} \\
(0.144)\end{array}$ & $\begin{array}{l}-0.389^{* * *} \\
(0.144)\end{array}$ \\
\hline Number children & $\begin{array}{l}-1.331^{* * *} \\
(0.247)\end{array}$ & $\begin{array}{l}-1.319^{* * *} \\
(0.246)\end{array}$ & $\begin{array}{l}-1.334^{* * * *} \\
(0.247)\end{array}$ & $\begin{array}{l}-1.328^{* * *} \\
(0.247)\end{array}$ & $\begin{array}{l}-1.329^{* * * *} \\
(0.247)\end{array}$ & $\begin{array}{l}-1.329^{* * *} \\
(0.245)\end{array}$ & $\begin{array}{l}-1.316^{* * *} \\
(0.244)\end{array}$ \\
\hline Wealth asset & & $\begin{array}{l}-0.704^{* * *} \\
(0.259)\end{array}$ & & & & & $\begin{array}{l}-0.668^{* *} \\
(0.262)\end{array}$ \\
\hline Medical aid (birth) & & & $\begin{array}{l}-0.741 \\
(1.015)\end{array}$ & & & & $\begin{array}{l}0.116 \\
(1.152)\end{array}$ \\
\hline Vitamin A (post) & & & & $\begin{array}{l}-0.828 \\
(0.904)\end{array}$ & & & $\begin{array}{l}-0.321 \\
(0.869)\end{array}$ \\
\hline Post birth visit & & & & & $\begin{array}{l}-0.743 \\
(1.000)\end{array}$ & & $\begin{array}{l}-0.180 \\
(1.078)\end{array}$ \\
\hline Tetanus injection & & & & & & $\begin{array}{c}-1.690^{*} \\
(0.869)\end{array}$ & $\begin{array}{l}-1.447+ \\
(0.884)\end{array}$ \\
\hline Observations & 1623 & 1623 & 1623 & 1623 & 1623 & 1623 & 1623 \\
\hline
\end{tabular}

$+\mathrm{p}<.13{ }^{*} \mathrm{p}<0.1,{ }^{*} \mathrm{p}<0.05,{ }^{* * *} \mathrm{p}<0.01$; standard errors are in parentheses; mother's age in five year intervals, ethnic group and community fixed-effects (CFE) are included.

Table 13: Number of children lost and ratio of deaths by maternal level of education for mothers who gave birth in the last five years

\begin{tabular}{ccccccccc}
\hline & \multicolumn{2}{c}{ No } & \multicolumn{2}{c}{ Primary school } & \multicolumn{2}{c}{ Middle school } & \multicolumn{3}{c}{ Total } \\
$\mathrm{N}$ & education & incomplete & completed & incomplete & completed & Total & freq. & p-value \\
\hline 0 & 66.7 & 69.6 & 73.3 & 75.5 & 77.9 & 71.1 & 1192 & 0.03 \\
1 & 19.4 & 18.7 & 20.4 & 18.1 & 14.3 & 18.7 & 314 & 0.71 \\
2 & 10.1 & 8.46 & 5.41 & 4.26 & 5.84 & 7.51 & 126 & 0.03 \\
$>2$ & 3.88 & 3.25 & 0.90 & 2.13 & 1.95 & 2.68 & 45 & 0.10 \\
Total & 100 & 100 & 100 & 100 & 100 & 100.0 & 1677 &. \\
\hline Ratio, mean & 8.17 & 7.70 & 6.86 & 6.41 & 5.74 & 7.32 & 1677 & 0.15 \\
Ratio, std dev & 13.4 & 13.6 & 13.2 & 13.0 & 12.2 & 13.3 &. &. \\
\hline
\end{tabular}




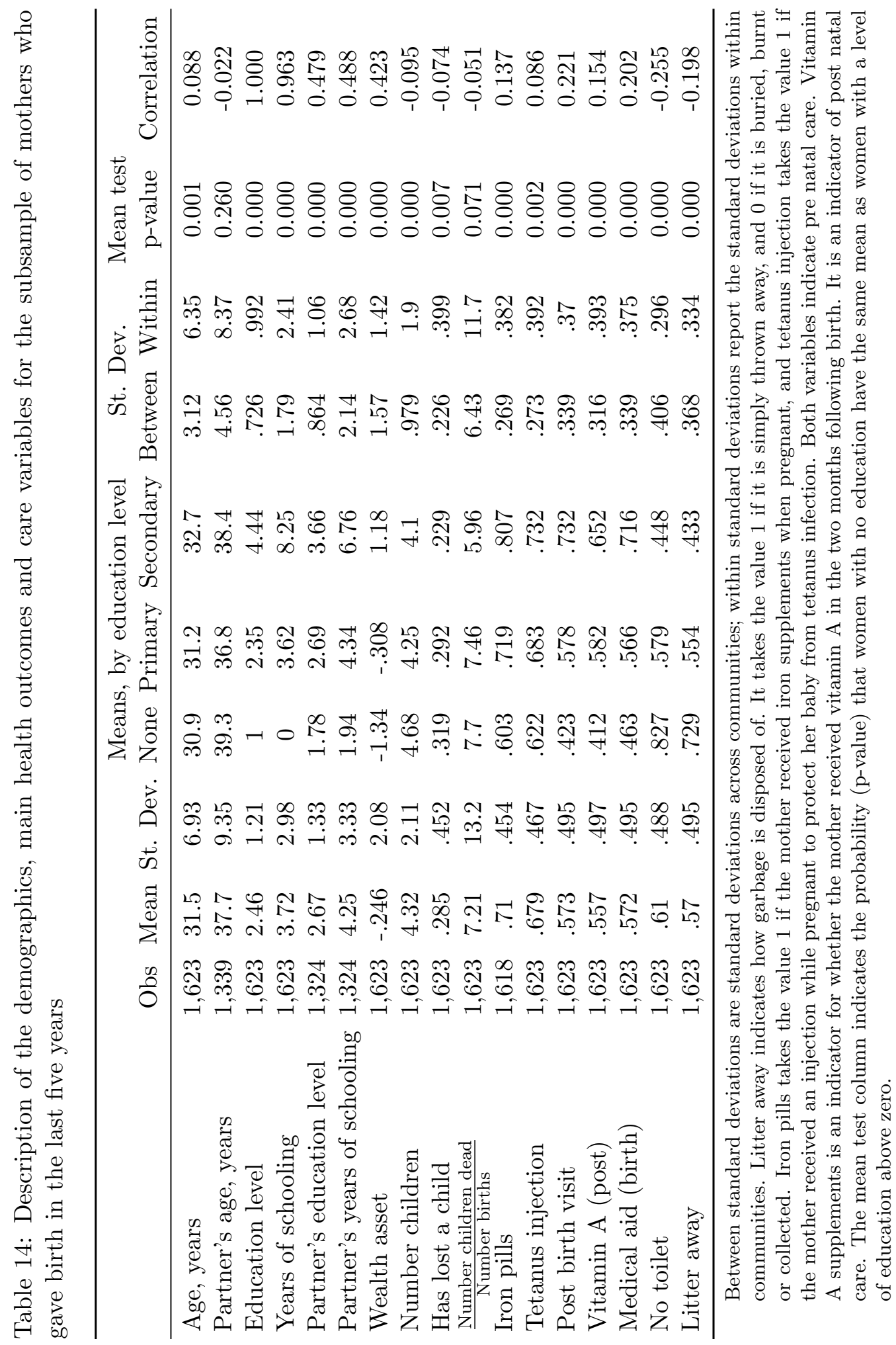


7 Appendix 
Table 15: Comparison of the sample of women who have ever given at least two births and over 18 with the subsample with instruments

\begin{tabular}{|c|c|c|c|c|c|c|c|}
\hline & \multicolumn{3}{|c|}{ All mothers } & \multicolumn{3}{|c|}{ Mothers with school information } & \multirow[b]{2}{*}{ p-value } \\
\hline & Obs & Mean & St. Dev. & Obs & Mean & St. Dev. & \\
\hline Sick & 2,892 & 0.149 & .357 & 2,745 & .146 & 0.353 & 0.699 \\
\hline Chronicle disease & 2,886 & 0.0613 & .24 & 2,739 & .0588 & 0.235 & 0.687 \\
\hline Works & 2,843 & 0.927 & .26 & 2,701 & .927 & 0.259 & 0.932 \\
\hline Hours of work & 2,608 & 1507.3 & 614 & 2,479 & 1506 & 613 & 0.951 \\
\hline Lives with partner & 2,386 & 0.975 & .155 & 2,278 & .978 & 0.147 & 0.530 \\
\hline Went to school & 2,892 & 0.765 & .424 & 2,745 & .764 & 0.425 & 0.933 \\
\hline Currently enrolled & 2,211 & 0.00136 & .0368 & 2,096 & .0014 & 0.038 & 0.948 \\
\hline Education level & 2,860 & 2.469 & 1.24 & 2,715 & 2.46 & 1.232 & 0.806 \\
\hline Years of schooling & 2,860 & 3.728 & 3.06 & 2,715 & 3.7 & 3.036 & 0.703 \\
\hline Partner's education level & 2,298 & 2.739 & 1.35 & 2,202 & 2.73 & 1.342 & 0.821 \\
\hline Partner's years of schooling & 2,298 & 4.441 & 3.4 & 2,202 & 4.41 & 3.374 & 0.751 \\
\hline Partner's age, years & 2,325 & 40.38 & 9.72 & 2,227 & 40.2 & 9.556 & 0.441 \\
\hline Wealth asset & 2,892 & 0.0499 & 2.32 & 2,745 & .0198 & 2.296 & 0.624 \\
\hline No toilet & 2,892 & 0.580 & .494 & 2,745 & .583 & 0.493 & 0.841 \\
\hline Litter away & 2,892 & 0.554 & .497 & 2,745 & .551 & 0.498 & 0.814 \\
\hline Safe drinking water & 2,892 & 0.281 & .449 & 2,745 & .279 & 0.448 & 0.862 \\
\hline Number children & 2,892 & 4.258 & 2.11 & 2,745 & 4.32 & 2.106 & 0.302 \\
\hline Number fostered children & 2,811 & 0.323 & .749 & 2,703 & .293 & 0.704 & 0.121 \\
\hline Number births & 2,892 & 4.711 & 2.39 & 2,745 & 4.77 & 2.404 & 0.381 \\
\hline Number children dead & 2,862 & 0.458 & .838 & 2,719 & .455 & 0.837 & 0.914 \\
\hline Has lost a child & 2,892 & 0.254 & .435 & 2,745 & .255 & 0.436 & 0.966 \\
\hline Number children dead & 2,892 & 6.785 & 13.8 & 2,745 & 6.53 & 12.984 & 0.476 \\
\hline $\begin{array}{l}\text { Number births } \\
\text { Iron pills }\end{array}$ & 1,731 & 0.708 & .455 & 1,698 & .708 & 0.455 & 0.989 \\
\hline Tetanus injection & 1,736 & 0.679 & .467 & 1,703 & .677 & 0.468 & 0.895 \\
\hline Post birth visit & 1,735 & 0.575 & .495 & 1,702 & .575 & 0.495 & 0.999 \\
\hline Vitamin A (post) & 1,736 & 0.556 & .497 & 1,703 & .555 & 0.497 & 0.954 \\
\hline Medical aid (birth) & 1,735 & 0.574 & .495 & 1,702 & .573 & 0.495 & 0.971 \\
\hline Age, years & 2,892 & 34.19 & 7.77 & 2,745 & 34.1 & 7.673 & 0.741 \\
\hline $11-15$ & 2,892 & 0.000 & .026 & 2,745 & 0 & 0 & \\
\hline $16-20$ & 2,892 & 0.0339 & .181 & 2,745 & .0306 & 0.172 & 0.485 \\
\hline $21-25$ & 2,892 & 0.126 & .332 & 2,745 & .128 & 0.334 & 0.884 \\
\hline $26-30$ & 2,892 & 0.197 & .398 & 2,745 & .201 & 0.401 & 0.683 \\
\hline $41-45$ & 2,892 & 0.132 & .339 & 2,745 & .128 & 0.334 & 0.667 \\
\hline $46-50$ & 2,892 & 0.0889 & .285 & 2,745 & .0845 & 0.278 & 0.562 \\
\hline Household size & 2,892 & 6.142 & 2.39 & 2,745 & 6.22 & 2.317 & 0.212 \\
\hline Number 6-10 girls & 2,892 & 0.579 & .722 & 2,745 & .594 & 0.727 & 0.438 \\
\hline Number $11-15$ girls & 2,892 & 0.379 & .603 & 2,745 & .39 & 0.609 & 0.475 \\
\hline Number 16-20 girls & 2,892 & 0.228 & .508 & 2,745 & .228 & 0.510 & 0.968 \\
\hline Number $21-25$ women & 2,892 & 0.195 & .434 & 2,745 & .194 & 0.430 & 0.941 \\
\hline Number 26-30 women & 2,892 & 0.219 & .424 & 2,745 & .223 & 0.426 & 0.742 \\
\hline Number 31-35 women & 2,892 & 0.206 & .409 & 2,745 & .207 & 0.409 & 0.991 \\
\hline Number $36-40$ women & 2,892 & 0.238 & .429 & 2,745 & .24 & 0.430 & 0.898 \\
\hline Number $41-45$ women & 2,892 & 0.145 & .352 & 2,745 & .14 & 0.347 & 0.567 \\
\hline Number 46-50 women & 2,892 & 0.110 & .314 & 2,745 & .105 & 0.308 & 0.545 \\
\hline Number $51-55$ women & 2,892 & 0.0218 & .148 & 2,745 & .0204 & 0.144 & 0.722 \\
\hline Number 20-60 women & 2,892 & 1.158 & .502 & 2,745 & 1.15 & 0.490 & 0.495 \\
\hline Number +60 women & 2,892 & 0.0401 & .203 & 2,745 & .0393 & 0.202 & 0.887 \\
\hline Number $11-15$ boys & 2,892 & 0.473 & .708 & 2,745 & .485 & 0.713 & 0.556 \\
\hline Number $16-20$ boys & 2,892 & $0.287 \quad 43$ & .603 & 2,745 & .291 & 0.606 & 0.766 \\
\hline Number 20-60 men & 2,892 & 1.024 & .611 & 2,745 & 1.02 & 0.601 & 0.956 \\
\hline Number + 60 men & 2,892 & 0.0705 & .267 & 2,745 & .0652 & 0.258 & 0.446 \\
\hline
\end{tabular}

The last column shows the two sided $\mathrm{p}$ value of the mean comparison test, i.e., the probability that both samples have the same mean. Questions on household members' age, work or schooling situation are answered for all members. Health questions are asked only to individuals present during the survey. 
Table 16: Comparison of the sample of women in the survey compared to the sample of women who answered the health survey

\begin{tabular}{|c|c|c|c|c|c|c|c|}
\hline & \multicolumn{3}{|c|}{ All women } & \multicolumn{3}{|c|}{ Women present } & \multirow[t]{2}{*}{ p-value } \\
\hline & Obs & Mean & St. Dev. & Obs & Mean & St. Dev. & \\
\hline Sick & 4,947 & 0.126 & .332 & 4,453 & .13 & 0.337 & 0.511 \\
\hline Chronicle disease & 4,936 & 0.0517 & .221 & 4,442 & .0531 & 0.224 & 0.750 \\
\hline Works & 4,716 & 0.924 & .266 & 4,274 & .922 & 0.268 & 0.780 \\
\hline Hours of work & 4,297 & 1462.7 & 628 & 3,895 & 1466 & 621.953 & 0.798 \\
\hline Lives with partner & 3,012 & 0.967 & .177 & 2,880 & .969 & 0.174 & 0.779 \\
\hline Went to school & 4,947 & 0.782 & 413 & 4,453 & .779 & 0.415 & 0.740 \\
\hline Currently enrolled & 3,869 & 0.0672 & .25 & 3,470 & .0559 & 0.230 & 0.044 \\
\hline Education level & 4,874 & 2.483 & 1.21 & 4,386 & 2.48 & 1.218 & 0.944 \\
\hline Years of schooling & 4,874 & 3.804 & 3.01 & 4,386 & 3.8 & 3.023 & 0.938 \\
\hline Partner's education level & 2,875 & 2.721 & 1.33 & 2,752 & 2.72 & 1.336 & 0.916 \\
\hline Partner's years of schooling & 2,875 & 4.396 & 3.37 & 2,752 & 4.39 & 3.365 & 0.915 \\
\hline Partner's age, years & 2,907 & 39.09 & 10.6 & 2,784 & 38.9 & 10.450 & 0.514 \\
\hline Wealth asset & 4,947 & 0.0986 & 2.38 & 4,453 & .0557 & 2.340 & 0.379 \\
\hline No toilet & 4,947 & 0.579 & .494 & 4,453 & .581 & 0.493 & 0.891 \\
\hline Litter away & 4,947 & 0.561 & .496 & 4,453 & .564 & 0.496 & 0.806 \\
\hline Safe drinking water & 4,947 & 0.281 & 449 & 4,453 & .278 & 0.448 & 0.745 \\
\hline Age, years & 5,294 & 28.43 & 10.1 & 4,453 & 29.8 & 9.691 & 0.000 \\
\hline $11-15$ & 4,947 & 0.0556 & .229 & 4,453 & .0429 & 0.203 & 0.004 \\
\hline $16-20$ & 4,947 & 0.211 & .408 & 4,453 & .19 & 0.393 & 0.011 \\
\hline $21-25$ & 4,947 & 0.150 & .357 & 4,453 & .156 & 0.363 & 0.431 \\
\hline $26-30$ & 4,947 & 0.146 & .353 & 4,453 & .157 & 0.364 & 0.137 \\
\hline $41-45$ & 4,947 & 0.0912 & .288 & 4,453 & .0934 & 0.291 & 0.706 \\
\hline $46-50$ & 4,947 & 0.0639 & .245 & 4,453 & .0627 & 0.242 & 0.808 \\
\hline Household size & 4,947 & 6.233 & 2.72 & 4,453 & 6.14 & 2.749 & 0.095 \\
\hline Number 6-10 girls & 4,947 & 0.498 & .689 & 4,453 & .505 & 0.695 & 0.646 \\
\hline Number $11-15$ girls & 4,947 & 0.430 & .65 & 4,453 & .407 & 0.635 & 0.088 \\
\hline Number $16-20$ girls & 4,947 & 0.450 & .672 & 4,453 & .417 & 0.660 & 0.015 \\
\hline Number 21-25 women & 4,947 & 0.253 & .502 & 4,453 & .252 & 0.500 & 0.917 \\
\hline Number 26-30 women & 4,947 & 0.186 & .4 & 4,453 & .193 & 0.406 & 0.375 \\
\hline Number $31-35$ women & 4,947 & 0.167 & .377 & 4,453 & .171 & 0.380 & 0.597 \\
\hline Number 36-40 women & 4,947 & 0.225 & .422 & 4,453 & .22 & 0.418 & 0.554 \\
\hline Number $41-45$ women & 4,947 & 0.152 & .359 & 4,453 & .147 & 0.354 & 0.433 \\
\hline Number 46-50 women & 4,947 & 0.138 & .347 & 4,453 & .13 & 0.339 & 0.270 \\
\hline Number 51-55 women & 4,947 & 0.0513 & .224 & 4,453 & .046 & 0.214 & 0.240 \\
\hline Number 20-60 women & 4,947 & 1.205 & .644 & 4,453 & 1.19 & 0.642 & 0.287 \\
\hline Number +60 women & 4,947 & 0.0534 & .23 & 4,453 & .051 & 0.225 & 0.611 \\
\hline Number $11-15$ boys & 4,947 & 0.470 & .726 & 4,453 & .462 & 0.721 & 0.581 \\
\hline Number $16-20$ boys & 4,947 & 0.334 & .654 & 4,453 & .31 & 0.645 & 0.076 \\
\hline Number 20-60 men & 4,947 & 1.047 & .712 & 4,453 & 1.04 & 0.703 & 0.880 \\
\hline Number + 60 men & 4,947 & 0.0910 & .295 & 4,453 & .0844 & 0.285 & 0.275 \\
\hline
\end{tabular}

The last column shows the two sided p value of the mean comparison test, i.e., the probability that both samples have the same mean. Questions on household members' age, work or schooling situation are answered for all members. Health questions are asked only to individuals present during the survey. 
Table 17: Main statistics, within and between standard deviations for infrastructure

\begin{tabular}{lcccccc}
\hline & \multicolumn{7}{c}{ Standard deviation } \\
& Mean & Overall & Between & Within & Min & Max \\
\hline Primary school & 0.848 & 0.359 & 0.207 & 0.294 & 0 & 1 \\
Middle school & 0.230 & 0.421 & 0.257 & 0.333 & 0 & 1 \\
High school & 0.056 & 0.229 & 0.096 & 0.208 & 0 & 1 \\
Health center & 0.460 & 0.498 & 0.287 & 0.409 & 0 & 1 \\
\hline
\end{tabular}

Between standard deviations report the standard deviations across communities while within standard deviations report the standard deviations inside communities.

Table 18: Cross-correlation table for infrastructure availability when parents were 10 years old

\begin{tabular}{lccccc}
\hline \multicolumn{1}{c}{ Variables } & Education & Primary & Middle & High school & Urban \\
\hline Primary school & 0.25 & 1.00 & & & \\
Middle school & 0.31 & 0.23 & 1.00 & & \\
High school & 0.28 & 0.10 & 0.45 & 1.00 & \\
Urban area & 0.26 & 0.07 & 0.37 & 0.61 & 1.00 \\
Health center & 0.24 & 0.33 & 0.50 & 0.26 & 0.20 \\
\hline
\end{tabular}

All pairwise correlations reported are significantly different from zero at the $1 \%$ level. 